\title{
On the role of the imide axial ligand in the spin and oxidation state of Mn corrole and corrolazine
} complexes

Gerard Alcover-Fortuny, ${ }^{\dagger}$ Rosa Caballol, ${ }^{\dagger}$ Kristine Pierloot, ${ }^{\ddagger}$ and Coen de

$$
\text { Graaf*, } \boldsymbol{\uparrow}, \dagger
$$

Departament de Química Física i Inorgànica, Universitat Rovira i Virgili, Marcel-lí Domingo s/n, 43007 Tarragona, Spain, Department of Chemistry, Celestijnenlaan 200F, B-3001 Heverlee-Leuven, Belgium, and Institució Catalana de Recerca i Estudis Avançats (ICREA), Passeig Lluis Companys 23, 08010, Barcelona, Spain

E-mail: coen.degraaf@urv.cat

${ }^{*}$ To whom correspondence should be addressed

${ }^{\dagger}$ Universitat Rovira i Virgili

$\ddagger$ University of Leuven

IICREA 


\begin{abstract}
Electronic structure calculations have been performed on four different Mn corrole and corrolazine complexes to clarify the role of the imide axial ligand on the relative stability of the different spin states and the stabilization of the high valent $\mathrm{Mn}$ ion in these complexes. Multiconfigurational perturbation theory energy calculations on the DFT optimized geometries shows that all complexes have a singlet ground state except the complex with the strongest electron withdrawing substituent on the imide axial ligand, which is found to have a triplet ground state. The analysis of the sigma and pi interaction between metal and imide ligand shows that this spin crossover is caused by a subtle interplay of geometrical factors ( $\mathrm{Mn}-\mathrm{N}$ distance and coordination angle) and the electron withdrawing character of the substituent on the imide, which reduces the electron donation to the metal centre. The analysis of the multiconfigurational wave functions reveals that the formally $\mathrm{Mn}^{\mathrm{V}}$ ion is stabilized by an important electron transfer from both the equatorial corrole/corrolazine ligand and the axial imide. The macrocycle donates roughly half an electron, being somewhere between the closed-shell trianionic and the dianionic radical form. The imide ligand transfers 2.5 electrons to the metal center, resulting in an effective d-electron count close to five in all complexes.
\end{abstract}

\title{
1 Introduction
}

The planar structure of transition metal (TM) porphyrins and their derivatives favours binding of axial ligands to the metal centre and is a key factor in many biological processes. Biomimetic TM porphyrins have been developed as synthetic catalysts, ${ }^{1-8}$ in which the energetics of the low-lying spin states as well as the factors stabilizing these states deserve special attention. In many cases, the axial ligand directly affects the magnetic properties and the reactivity of these compounds. For instance, in Mn porphyrin complexes reduction of the low-spin $(\mathrm{S}=0) \mathrm{Mn}^{\mathrm{V}}$ complex with a closed-shell $\mathrm{d}^{2}$ electronic configuration (Fig.1, centre right) to $\mathrm{a} \mathrm{d}^{3} \mathrm{Mn}^{\mathrm{IV}}$ complex implies not only the addition of one electron but also the 
promotion of an electron from $3 \mathrm{~d}_{x y}$ to $3 \mathrm{~d}_{x z}$ or $3 \mathrm{~d}_{y z}$ and the consequent change to a high-spin $(\mathrm{S}=3 / 2)$ configuration (Fig.1 centre left). ${ }^{9-11}$ Changes in the axial ligand can stabilize the $\mathrm{Mn}^{\mathrm{V}} 3 \mathrm{~d}_{x z, y z}$ orbitals favouring the high-spin $(\mathrm{S}=1)$ state (Fig.1 right) and facilitating the reduction to $\mathrm{Mn}^{\mathrm{IV}}$.

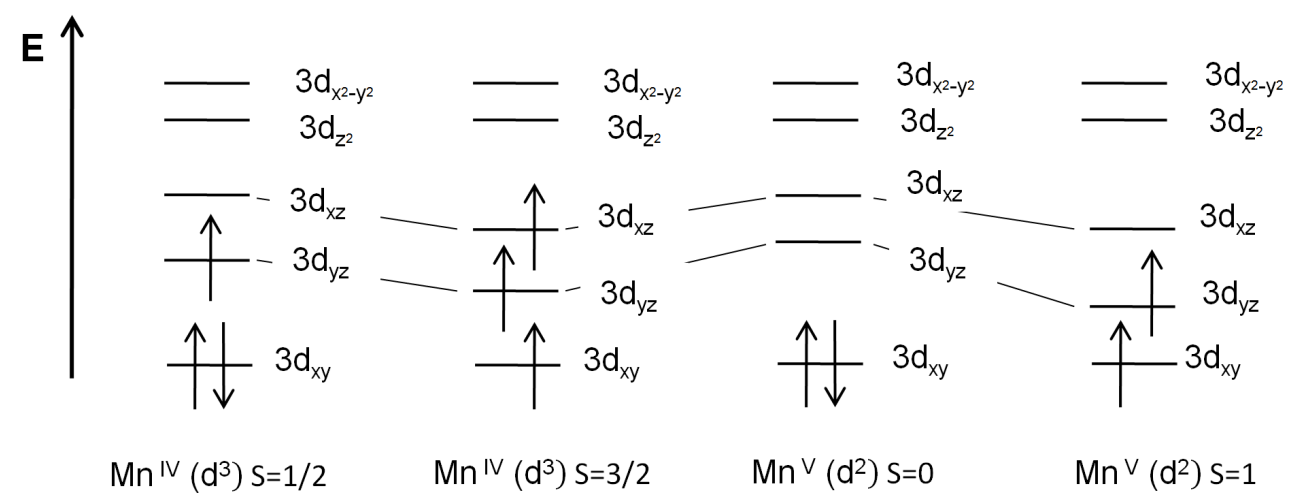

Figure 1: Low- $(\mathrm{S}=1 / 2)$ and high-spin $(\mathrm{S}=3 / 2) \mathrm{Mn}^{\mathrm{IV}}$ (left) and low- $(\mathrm{S}=0)$ and high-spin $(\mathrm{S}=1) \mathrm{Mn}^{\mathrm{V}}$ (right) spin configurations of the $\mathrm{Mn}$ ion in the quasi-square pyramid coordination sphere of the oxo-Mn(porphyrin) system with the nitrogens of the pyrrole rings placed on the $x$ - and $y$-axes.

This example shows how porphyrin stabilizes transition metal ions with unusually high oxidation states, ${ }^{12}$ but corrole (Cor), one meso carbon atom shorter, has been postulated to be even more effective for this purpose. The most important difference in the corrole structural skeleton with respect to porphyrin (Fig.2) is that while the latter coordinates to the metal as a dianionic ligand, the former is trianionic. ${ }^{13}$ Although corrole was first reported in $1964,{ }^{14}$ the interest in this macrocycle has increased since 1999 when simpler synthetic pathways were developed, ${ }^{15-17}$ emphasizing the large application range of corrole and its TM complexes. ${ }^{18,19}$ This interest has resulted in several experimental and theoretical studies on corrole X-ray structure, spectroscopy and electronic structure. ${ }^{20-25}$

The formal oxidation states of TMs in corrole are higher than in porphyrin but the metal centre in a $[\mathrm{TM}(\mathrm{Cor})]$ is not necessarily high-valent and sometimes, corrole is expected to act as a dianionic radical instead of a closed-shell trianion. It has been suggested that low oxidation states can be stabilized by the coupling with non-innocent corrole ligands in some 
copper and iron complexes. ${ }^{20,26,27}$ However, the electronic structure of the triplet state in $\mathrm{Mn}^{\mathrm{V}}$ corroles is attributed to a high spin $(\mathrm{S}=1) \mathrm{Mn}^{\mathrm{V}}$ (Fig.1 right) with an innocent, closedshell trianionic corrole, due to the high energy of the low spin $(\mathrm{S}=1 / 2) \mathrm{Mn}^{\mathrm{IV}}$ (Fig.1 left) ferromagnetically coupled to a one-electron radical dianionic corrole acting as a non-innocent ligand. ${ }^{23}$ Once again, the nature of the axial ligand is a crucial factor in this non-innocent behaviour. The capability of corrole to stabilize unusual oxidation states of TM has often been attributed both to its 3 - charge and to its strong $\sigma$-donor ligand field. The cavity size of the more recent corrolazine $(\mathrm{Cz})$ derivative, first synthesized in $2001,{ }^{28}$ is smaller than in corrole, which enhances the $\sigma$-donation. In addition, the meso-substituted nitrogen atoms (Fig.2) are more electronegative than carbon and contribute to the electron-deficiency of the coordination sphere, favouring the 3 - charge of the ligand over the dianionic radical state. ${ }^{29,30}$

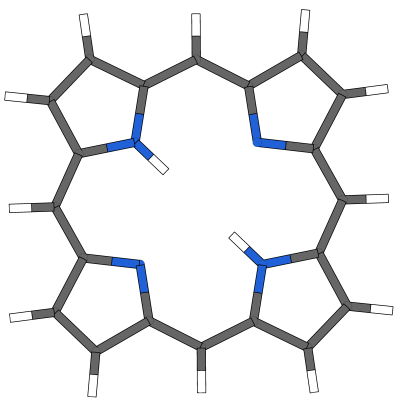

porphyrin

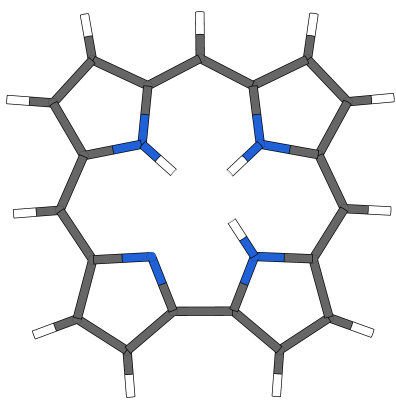

corrole

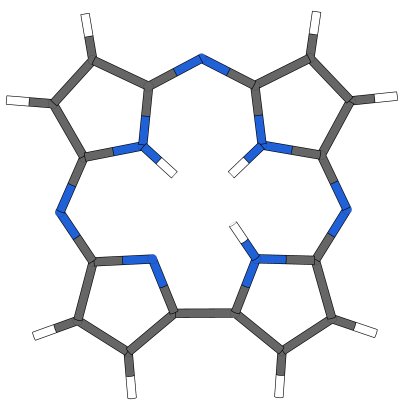

corrolazine

Figure 2: Porphyrin, the one meso carbon atom shorter derivative corrole, and its nitrogen meso-substituted derivative, corrolazine.

As seen above, small structural variations in the axial ligand and the macrocycle result in important changes in the spin and oxidation state of the metal centre, which directly affects the reactivity of the complex. ${ }^{31}$ In order to catalyze oxygen transfer reactions, $[\mathrm{Mn}(\mathrm{Cor})(\mathrm{O})]^{32-35}$ and $[\mathrm{Mn}(\mathrm{Cz})(\mathrm{O})]^{36-38}$ have been synthesized. Similarly to their oxo derivatives, imido- (NR) manganese corrole and corrolazine have attracted interest due to their potential applications, but not much is known about their properties. [Mn(tpfc)(NMes)] $\left(\mathrm{tpfc}=\operatorname{tris}(\right.$ pentafluorophenyl)corrole $),[\mathrm{Mn}(\mathrm{tpfc})(\mathrm{NtClPh})],{ }^{39,40}[\mathrm{Mn}(\mathrm{tbpcz})(\mathrm{NMes})](\mathrm{tbpcz}$ 
$=\operatorname{octakis}(p$-tert-butylphenyl $)$ corrolazine $)^{41}$ and $[\mathrm{Mn}(\mathrm{tpfc})(\mathrm{NTs})]^{42}$ are the few examples reported. NMes, NtClPh and NTs (Fig.3) axially coordinate to the metal as dianionic ligands with distances typically assigned to a $\mathrm{M} \equiv \mathrm{N}$ bond, giving rise to neutral complexes with formally high-valent $\mathrm{Mn}^{\mathrm{V}}$. Interestingly, while complexes with $\mathrm{NMes}$ and $\mathrm{NtClPh}$ are characterized as diamagnetic $(\mathrm{S}=0)$ by ${ }^{1} \mathrm{H}$ and ${ }^{19} \mathrm{~F}$ NMR spectroscopy, magnetic measurements on the NTs derivative give a magnetic moment associated with a paramagnetic $(\mathrm{S}=1)$ state on the $\mathrm{Mn}^{\mathrm{V}} .{ }^{43}$ No low-lying $\mathrm{Mn}^{\mathrm{IV}}$ states with a radical on corrole or corrolazine are expected since they are high-lying in the oxo derivatives. ${ }^{23}$ The present work describes a comprehensive DFT and CASPT2 computational study on imido-Mn corrole and corrolazine complexes. It focuses on the geometrical parameters, the lowest $\mathrm{Mn}(\mathrm{S}=0)$ and $(\mathrm{S}=1)$ spin states and the role of the three main actors (metal, macrocycle and imide) on the spin and oxidation states of $[\mathrm{Mn}(\mathrm{Cor})(\mathrm{NMes})],[\mathrm{Mn}(\mathrm{Cz})(\mathrm{NMes})],[\mathrm{Mn}(\mathrm{Cor})(\mathrm{NtClPh})]$ and $[\mathrm{Mn}(\mathrm{Cor})(\mathrm{NTs})]$. The main conclusion from the DFT and CASPT2 calculations is that for the NTs ligand the weak $\pi$-donation and the Mn- $\mathrm{N}_{a x i a l}-\mathrm{S}$ coordination angle favour a triplet ground state. An orthogonal valence bond analysis of the electronic structure of the four complexes reveals that nearly 3 electrons ( 0.5 from corrole and 2.5 from the ligand) are transferred to the metal centre, stabilizing the TM ion.

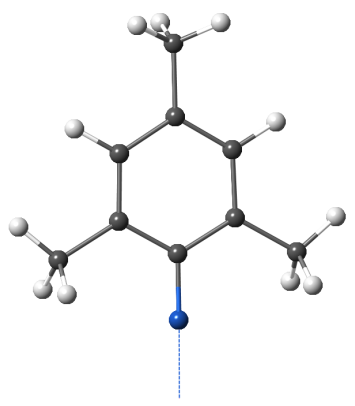

NMes

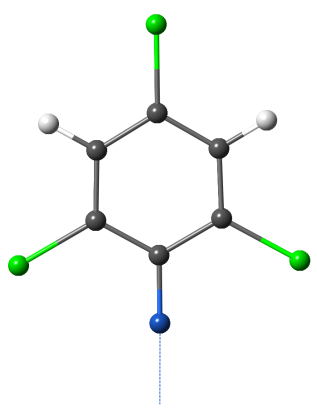

$\mathrm{NtClPh}$

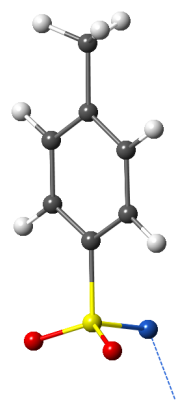

NTs

Figure 3: Axial imide ligands N-mesityl (NMes), N-(2,4,6-trichlorophenyl) (NtClPh) and N-tosyl (NTs). 


\section{Computational Information}

DFT geometry optimizations have been carried out using the def2-TZVP basis set ${ }^{44,45}$ and the BP86 ${ }^{46,47}$ functional with Turbomole 6.4. ${ }^{48}$ Cartesian coordinates, energies and other information related to these calculations are available in ioChem-BD Platform. ${ }^{49} \mathrm{CASSCF}$ and CASPT2 single point calculations have been performed with Molcas $7.8^{50}$ on top of the BP86 optimized geometries. Basis I (Mn ANO-rcc ${ }^{51,52}$ contracted to [7s6p5d2f1g]; N, C, O, S, Cl ANO-s ${ }^{53}$ contracted to [4s3p1d]; H ANO-s contracted to [2s]) and Basis II (ANO-rcc on all atoms contracted to [7s6p5d3f2g1h] for Mn, [4s3p2d1f] for N, C, O, S, Cl and [3s1p] for H) have been compared. The $[10,12]$ active space consists of the Mn $3 \mathrm{~d}$ orbitals $\left(3 \mathrm{~d}_{x z}, 3 \mathrm{~d}_{y z}\right.$, $3 \mathrm{~d}_{x y}, 3 \mathrm{~d}_{x^{2}-y^{2}}$ and $\left.3 \mathrm{~d}_{z^{2}}\right)$, three diffuse orbitals that account for the double shell effect $\left(4 \mathrm{~d}_{x z}\right.$, $4 \mathrm{~d}_{y z}$ and $\left.4 \mathrm{~d}_{x y}\right)$, and four ligand orbitals $\left(2 \mathrm{p}_{x}, 2 \mathrm{p}_{y}\right.$ and $2 \mathrm{p}_{z}$ for $\mathrm{N}_{\text {axial }}$ and $\sigma$ for $\left.\mathrm{N}_{\text {pyrrole }}\right)$. This active space is required to obtain an accurate reference wave function. ${ }^{54}$ Instead of being localized, the Mn 3d and ligand orbitals form bonding and anti-bonding combinations. The orientation of the system with the $\mathrm{N}_{\text {pyrrole }}$ on the $x$ - and $y$-axes makes that $\mathrm{Mn} 3 \mathrm{~d}_{x z}, 3 \mathrm{~d}_{y z}$ and $3 \mathrm{~d}_{z^{2}}$ interact with $\mathrm{N}_{\text {axial }} 2 \mathrm{p}_{x}, 2 \mathrm{p}_{y}$ and $2 \mathrm{p}_{z}$ orbitals to form a bonding and anti-bonding pair of orbitals with occupations close to 2 and 0 respectively. Mn $3 \mathrm{~d}_{x^{2}-y^{2}}$ combines with $\mathrm{N}_{\text {pyrrole }} 2 \mathrm{p}_{x}$ and $2 \mathrm{p}_{y}$ to form $\sigma$ and $\sigma^{*}$ orbitals. Mn $3 \mathrm{~d}_{x y}$ is non-bonding and more stable than the anti-bonding combinations.

To make feasible the DDCI calculations ${ }^{55,56}$ which have been performed using the CASDI $\operatorname{code}^{57}$ a significant reduction of the molecular orbital space is required. The doubly occupied and empty CASSCF orbitals have been localized following the scheme outlined in Ref., ${ }^{5-60}$ and subsequently, classified in terms of core, $\sigma$ and $\pi$ orbitals to select the most relevant orbitals to be taken into account in the DDCI calculation. Two molecular orbital spaces were considered, the first contains the $\pi$ and $\pi^{*}$ orbitals in addition to the twelve active orbitals, the second space extends the first one with the Mn 3s-3p orbitals. The reference wave function for the DDCI calculation is constructed from a [2,2]-CASCI calculation using the orbitals that are singly occupied in the triplet state; $3 \mathrm{~d}_{x y}$ and $\left(3 \mathrm{~d}_{x z}-2 \mathrm{p}_{x}\right)^{*}$ or $\left(3 \mathrm{~d}_{y z}-2 \mathrm{p}_{y}\right)^{*}$ 
depending on the complex.

\section{Results and Discussion}

\subsection{DFT geometry optimizations}

The geometries of the four neutral imido-complexes have been optimized for both singlet and triplet states. The resulting distances and angles are in good agreement with available experimental data, the most important structural parameters and the relative energies of these BP86 calculations are summarized in the Supporting Information. In the low-spin state all four ligands axially bind to the $\mathrm{Mn}(\mathrm{Cor})$ and $\mathrm{Mn}(\mathrm{Cz})$ moieties in a linear fashion, forming a $\mathrm{Mn} \equiv \mathrm{N}$ bond, typical of imido-complexes. In all cases the Mulliken spin density in the triplet state gives almost 2.3 alpha electrons on the metal centre and 0.2 beta electrons on $\mathrm{N}_{\text {axial }}$, confirming that in this state the unpaired electrons are localized on Mn. This indicates that states with a radical on corrole or corrolazine are higher in energy (see Fig. $4)$.

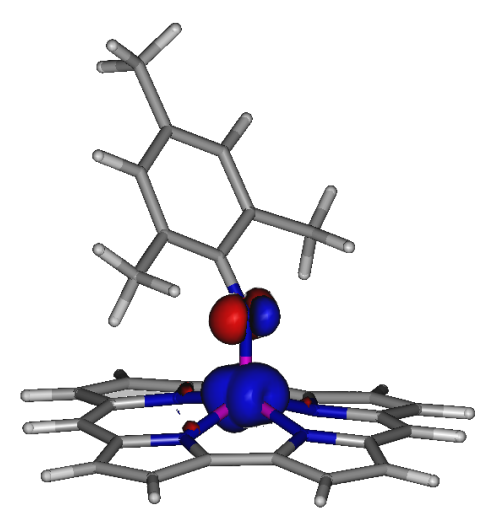

Figure 4: Spin density in the $[\mathrm{Mn}(\mathrm{Cor})(\mathrm{NMes})]$ triplet state BP86/def2-TZVP optimized geometry (isocontour $=0.009$ ).

As expected, corrolazine coordinates to Mn with shorter distances (1.89 $\AA-1.91 \AA)$ than corrole $(1.91 \AA-1.95 \AA)$ due to the smaller cavity size, which is also responsible for a larger out of $\mathrm{N}_{\text {pyrrole }}$ plane displacement of the metal centre $(0.59 \AA$ for corrolazine and $0.54 \AA$ - 
$0.56 \AA$ depending on the axial ligand for corrole). This out of $\mathrm{N}_{\text {pyrrole }}$ plane displacement is noticeable in all complexes and induces bonding and anti-bonding mixing between the $\mathrm{N}_{\text {pyrrole }} \sigma$ and the $3 \mathrm{~d}_{x z, y z}$ orbitals (see Fig. 5). The increased mixing widens the gap between the $3 \mathrm{~d}_{x y}$ and the $3 \mathrm{~d}_{x z, y z}$ orbitals, favouring the double occupation of the Mn- $3 \mathrm{~d}_{x y}$ orbital and stabilizing the singlet state. ${ }^{61}$ In the triplet state, the distance between $\mathrm{Mn}$ and the axial ligand increases due to the occupation of one of the $\pi$ anti-bonding $\left(3 \mathrm{~d}_{x z}-2 \mathrm{p}_{x}\right)^{*}$ or $\left(3 \mathrm{~d}_{y z}-2 \mathrm{p}_{y}\right)^{*}$.

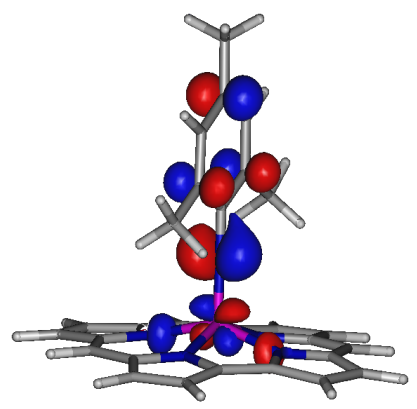

$\left(3 \mathbf{d}_{x z}-2 \mathbf{p}_{x}\right)^{*}$

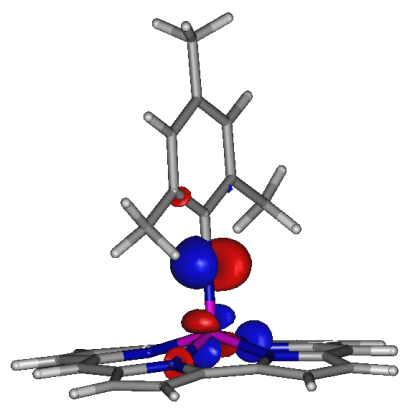

$\left(3 \mathbf{d}_{y z}-\mathbf{2} \mathbf{p}_{y}\right)^{*}$

Figure 5: Anti-bonding mixing of $2 \mathrm{p}_{x, y} \mathrm{~N}_{\text {axial }}$ and $\sigma \mathrm{N}_{\text {pyrrole }}$ orbitals with $3 \mathrm{~d}_{x z, y z}$ of $\mathrm{Mn}$ (isocontour $=0.05$ ).

\subsection{Multiconfigurational wave function calculations}

DFT is known to provide suitable geometries for most TM complexes, but it is more complicated to precisely estimate the relative energies of different spin states. ${ }^{62-64}$ In general, local density and gradient corrected functionals tend to overestimate the stability of the low-spin states. In line with this observation, we observe that the BP86 calculations predict singlet ground states for all the imide derivatives. However, these results are not completely consistent with experimental data in $[\mathrm{Mn}(\mathrm{Cor})(\mathrm{NTs})]$, which is assigned as a triplet by magnetic susceptibility measurements. Therefore, we will now proceed with the discussion of the multiconfigurational wave function description of the electronic states, which gives, in principle, more accurate relative energies. 


\subsubsection{Single point energy calculations}

Results of $[10,12]$-CASPT2 calculations are summarized in Table 1 and predict singlet ground states for all complexes except for the NTs complex with the weakest $\pi$-donating axial ligand for which both spin states are predicted to be nearly degenerate. The second triplet state of the complex with the $\mathrm{NtClPh}$ ligand, which is of intermediate $\pi$-donating strength, has a lower relative energy than the second triplet state in the NMes complex, which has the strongest $\pi$-donating ligand. This shows that the stronger electron-donation increases the $3 \mathrm{~d}_{x z, y z}$ relative orbital energies. A considerable energy gap separates the first and second triplets of all imido-complexes contrasting with complexes with the cylindrically symmetric oxo axial ligands, for which the two high-spin states are degenerate. ${ }^{23}$

Table 1: [10,12]-CASPT2 main configurations and relative energies (in $\mathrm{eV}$ ) of the singlet and triplet states obtained with the BP86/TZVP optimized geometries.

\begin{tabular}{|c|c|c|c|}
\hline & \multirow[b]{2}{*}{ main configuration } & \multicolumn{2}{|c|}{$10,12]-C A S P T 2$} \\
\hline & & Basis I & Basis II \\
\hline \multicolumn{4}{|l|}{$[\mathrm{Mn}(\mathrm{Cor})(\mathrm{NMes})]$} \\
\hline $\mathrm{S}=0$ & $\left(3 d_{x y}\right)^{2}$ & 0.00 & 0.00 \\
\hline \multirow[t]{2}{*}{$\mathrm{S}=1$} & $\left(3 d_{x y}\right)^{1}\left(3 d_{x z}-2 p_{x}\right) *^{1}$ & 0.17 & 0.18 \\
\hline & $\left(3 d_{x y}\right)^{1}\left(3 d_{y z}-2 p_{y}\right) *^{1}$ & 1.19 & 1.18 \\
\hline \multicolumn{4}{|l|}{$[\mathrm{Mn}(\mathrm{Cz})(\mathrm{NMes})]$} \\
\hline $\mathrm{S}=0$ & $\left(3 d_{x y}\right)^{2}$ & 0.00 & 0.00 \\
\hline \multirow[t]{2}{*}{$\mathrm{S}=1$} & $\left(3 d_{x y}\right)^{1}\left(3 d_{x z}-2 p_{x}\right) *^{1}$ & 0.24 & 0.25 \\
\hline & $\left(3 d_{x y}\right)^{1}\left(3 d_{y z}-2 p_{y}\right) *^{1}$ & 1.19 & 1.19 \\
\hline \multicolumn{4}{|l|}{$[\mathrm{Mn}(\mathrm{Cor})(\mathrm{NtClPh})]$} \\
\hline $\mathrm{S}=0$ & $\left(3 d_{x y}\right)^{2}$ & 0.00 & 0.00 \\
\hline \multirow[t]{2}{*}{$\mathrm{S}=1$} & $\left(3 d_{x y}\right)^{1}\left(3 d_{x z}-2 p_{x}\right) *^{1}$ & 0.16 & 0.17 \\
\hline & $\left(3 d_{x y}\right)^{1}\left(3 d_{y z}-2 p_{y}\right) *^{1}$ & 0.85 & 0.87 \\
\hline \multicolumn{4}{|l|}{$[\mathrm{Mn}(\mathrm{Cor})(\mathrm{NTs})]$} \\
\hline $\mathrm{S}=0$ & $\left(3 d_{x y}\right)^{2}$ & 0.00 & 0.00 \\
\hline$S=1$ & $\left(3 d_{x y}\right)^{1}\left(3 d_{y z}-2 p_{y}\right) *^{1}$ & -0.02 & 0.00 \\
\hline
\end{tabular}

The Mn- $\mathrm{N}_{\text {axial }}-\mathrm{R}$ angle of the triplet state geometries is not linear, diminishing the overlap of the $\left(3 \mathrm{~d}_{x z}-2 \mathrm{p}_{x}\right)$ or the $\left(3 \mathrm{~d}_{y z}-2 \mathrm{p}_{y}\right)$ pair of orbitals. Taking as example the NTs complex in the triplet state (see Fig.6), the axial ligand is bend towards the $y$ axis and the mixing 
between $3 \mathrm{~d}_{y z}$ and $2 \mathrm{p}_{y}$ is smaller than between $3 \mathrm{~d}_{x z}$ and $2 \mathrm{p}_{x}$. As a consequence, the antibonding $\left(3 \mathrm{~d}_{y z}-2 \mathrm{p}_{y}\right) *$ orbital is stabilized and its occupation is favoured. ${ }^{42}$ When compared to corrole, the smaller cavity size of corrolazine results in a shortening of the $\mathrm{Mn}-\mathrm{N}_{\text {pyrrole }}$ bond and an increase of the out of $\mathrm{N}_{\text {pyrrole }}$ plane displacement, giving rise to an even more unstable triplet state. The energy of the triplet state of $[\mathrm{Mn}(\mathrm{Cor})(\mathrm{NTs})]$ is found at a much lower energy with CASPT2 than with BP86, but the description is still not consistent with the experimental data.

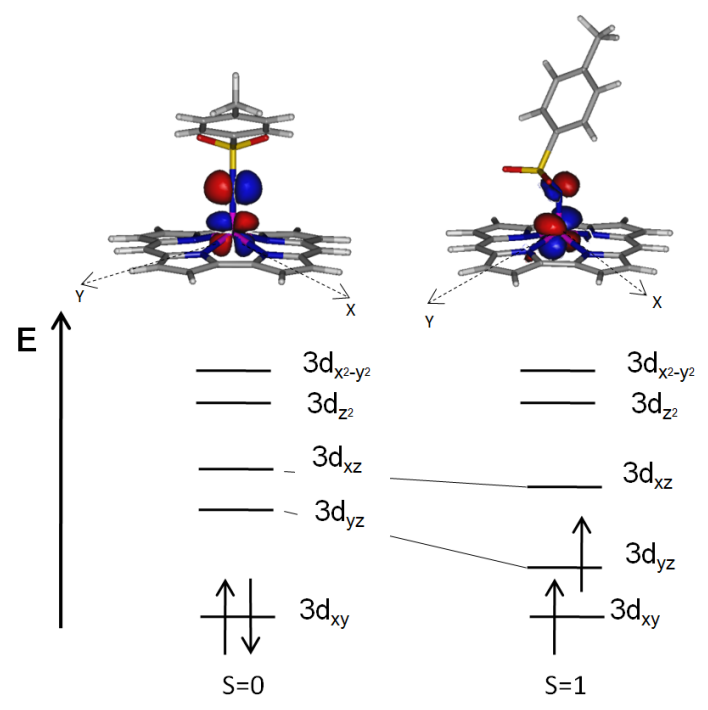

Figure 6: Schematic representation of the energetic ordering of the molecular orbitals for the singlet (left) and first triplet (right) states of $[\mathrm{Mn}(\mathrm{Cor})(\mathrm{NTs})]$ (isocontour $=0.05$ ).

\subsubsection{Reoptimization of $[\mathrm{Mn}(\mathrm{Cor})(\mathrm{NTs})]$}

The near-degeneracy of the singlet and lowest triplet state of the NTs complex triggers the need to reconsider the geometry optimization performed with the BP86 functional. In many cases reoptimization of some key geometrical parameters with CASPT2 can lead to important improvements in the relative energies of interest. ${ }^{65}$ In this case the most obvious parameters to be reoptimized are the Mn-N distance and the Mn-N-S angle. The BP86 optimized geometries have been taken as starting point for the singlet and triplet states, respectively, for a $[10,12]$-CASPT2 scan along the axial coordination distance. At each 
point of the scan, the $\mathrm{Mn}-\mathrm{N}_{\text {axial }}$ distance and the Mn-N-S angle were kept fixed at a certain value while the rest of structural parameters was optimized with BP86/TZVP. CASPT2 single point calculations with Basis I have been performed to evaluate the energy of the so-obtained geometries. Since the axial coordination angle is linear in the singlet geometry, the angle was only scanned for the triplet state.

As can be seen in Table 2, [10,12]-CASPT2 calculations with Basis I and Basis II predict the experimentally expected high-spin ground state and a reasonable gap with the singlet state. Comparison of the [10,12]-CASPT2/BP86 geometries with those reported in the Supporting Information reveals that small variations in the $\mathrm{Mn}-\mathrm{N}_{\text {axial }}$ distance (on the order of $0.03 \AA)$ and the $\mathrm{Mn}-\mathrm{N}_{\text {axial }}-\mathrm{S}$ angle $\left(\sim 10^{\circ}\right)$ can remove the degeneracy of the $\mathrm{S}=0$ and $\mathrm{S}=1$ states of these complexes. At difference with the other imido-complexes, NTs contains a tetrahedral sulphur atom between $\mathrm{N}_{a x i a l}$ and the phenyl ring (see Fig. 3), giving flexibility to the structure of the axial ligand and favouring geometries with a non-linear coordination angle. In conclusion, being the weaker $\pi$-donating ligand and favouring bent axial angles, NTs accomplishes all the factors to exhibit a triplet ground state.

Table 2: Main electronic configurations, reoptimized $\mathrm{Mn}-\mathrm{N}_{\text {axial }}$ distances (in $\AA$ ) and $\mathrm{Mn}-$ $\mathrm{N}_{\text {axial }}-\mathrm{S}$ angles (in degrees), and relative energies (in $\mathrm{eV}$ ) of the singlet and triplet states of the NTs imido-complex. BP86 results of Sec. 3.1 in parenthesis for comparison.

\begin{tabular}{ccccc}
\hline & & \multicolumn{2}{c}{ CASPT2 } \\
& Mn-N $\mathrm{N}_{\text {axial }}$ & Mn-N axial $^{-} \mathrm{S}$ & Basis I & Basis II \\
\hline$\left(3 d_{x y}\right)^{2}$ & 1.60 & 168.2 & 0.00 & 0.00 \\
$\left(3 d_{x y}\right)^{1}\left(3 d_{y z}-2 p_{y}\right) *^{1}$ & $(1.62)$ & $(167.0)$ & & \\
& 1.75 & 125.0 & -0.08 & -0.07 \\
& $(1.71)$ & $(132.0)$ & & \\
\hline
\end{tabular}

\subsubsection{Core correlation: a CASPT2 and DDCI comparison}

The addition by perturbative methods of the electron correlation that is not taken into account in the CASSCF approach leads to important changes of the relative energy of the spin states in the here-studied imido-complexes and brings the theoretical estimates in good 
agreement with experimental data. Being of moderate computational cost, CASPT2 seems to be a very efficient computational strategy to obtain accurate relative energies of spin states. The validity of applying a level shift of 0.1 Eh to avoid the appearance of intruder states and the choice of the zeroth-order Hamiltonian with IPEA equal to 0.25 is well-established and the only point that deserves further attention is the accuracy of the pertubative estimate of the core correlation. Typically, the core electrons of main group elements are excluded from the CASPT2 energy estimation, since they do not introduce any differential effect on the energies of spin states. In the case of first-row transition metals, the situation is slightly different because the semi-core 3s-3p electrons can change the relative energy of the spin states by $\sim 0.1-0.2 \mathrm{eV}$ when included in the multireferential second-order perturbative correction $^{66}$. However, recent results by Pierloot et al. ${ }^{67}$ indicate that the correlation energy description by CASPT2 of these electrons is probably not fully consistent leading to wrong estimations of the high and low-spin energies in some cases.

In order to validate the multiconfigurational calculations of the present work, the Mn 3s-3p CASPT2 electron correlation in all the imido-complexes has been compared with a variational estimate obtained by DDCI. ${ }^{55,56}$ As can be seen in Table 3, the CASPT2 3s-3p contribution is quantitatively similar for all complexes and in all cases stabilizes the triplet state by around $0.2 \mathrm{eV}$. The importance of $3 \mathrm{~s}-3 \mathrm{p}$ correlation is reflected in the fact that it inverts the ground state of $[\mathrm{Mn}(\mathrm{Cor})(\mathrm{NTs})]$. The [2,2]-DDCI estimate of the 3s-3p correlation contributions to the triplet-singlet energy difference are slightly lower than those calculated with $[10,12]$-CASPT2 but no relevant differences are detected. The addition of more virtual orbitals in the DDCI calculation increases the correlation energy, but has no differential effects. 
Table 3: [10,12]-CASPT2 and [2,2]-DDCI estimates of the Mn 3s-3p electron correlation contribution (in $\mathrm{eV}$ ) to the triplet-singlet energy difference for the four imido-complexes.

\begin{tabular}{lcc}
\hline & {$[10,12]-C A S P T 2$} & {$[2,2]-D D C I$} \\
\hline$[\mathrm{Mn}(\mathrm{Cor})(\mathrm{NMes})]$ & -0.24 & -0.13 \\
{$[\mathrm{Mn}(\mathrm{Cz})(\mathrm{NMes})]$} & -0.25 & -0.17 \\
{$[\mathrm{Mn}(\mathrm{Cor})(\mathrm{NtClPh})]$} & -0.11 & -0.13 \\
{$[\mathrm{Mn}(\mathrm{Cor})(\mathrm{NTs})]$} & -0.21 & -0.11 \\
\hline
\end{tabular}

\subsubsection{Wave function analysis}

The assignment of charges to atoms (or groups of atoms) in a molecule is a delicate matter. The atomic charge is not observable and computationally derived charges show a large dependence on the strategy applied to calculate them. Without pretending to determine exact charges, we have used an orthogonal valence bond reading of the multiconfigurational wave function to extract more information about the electronic structure and assign populations to the $\mathrm{Mn}$ atom in the different complexes. Atomic-like and fragment orbitals are ideally suited to describe many chemical concepts in terms of the valence bond theory in an intuitive manner, ${ }^{68}$ but they are computationally speaking not the most ideal choice as orbital basis. On the other hand, CASSCF wave functions are normally expressed with molecular orbitals, computationally much simpler to handle and also because they give direct information about molecular spectroscopy and ionization potentials, among other properties. ${ }^{\text {A }}$ unitary transformation of the CASSCF active orbitals is performed to maximize the weight of the metal basis functions giving atomic-like orbitals and, as a consequence of the rotation process, the weight of the ligands in the others. The wave function is invariant upon this transformation. The re-expression of the multiconfigurational CASSCF wave function in this new orbital basis makes possible to capture the electronic structure in similar intuitive concepts as in traditional valence bond calculations. ${ }^{69}$ This orthogonal valence bond analysis has been used before to study TM-ligand interactions. ${ }^{70-73}$ The effect of orbital localization is illustrated in Fig. 7 and transfers the covalency contained in the delocalized orbitals to 
the configuration expansion. ${ }^{74,75}$ In the present case all twelve orbitals of the active space have been localized.

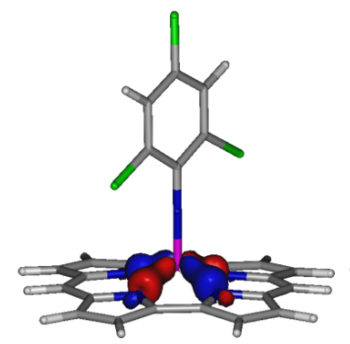

$\operatorname{Mn}-\operatorname{Cor}(\sigma)$

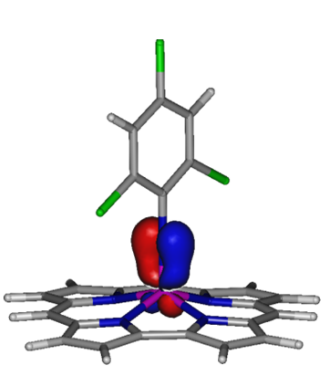

$\left(3 d_{x z}-2 p_{x}\right)$

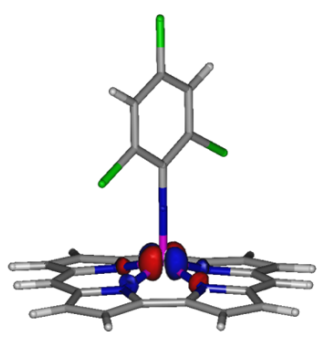

$\operatorname{Mn}-\operatorname{Cor}\left(\sigma^{*}\right)$

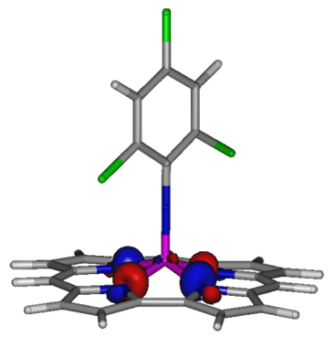

Cor $(n)$

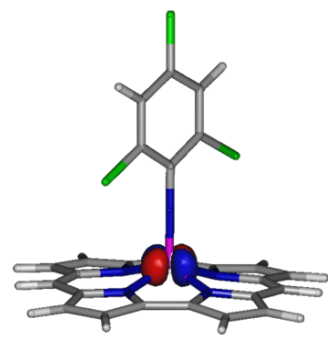

$\operatorname{Mn}\left(3 d_{x_{2}-y^{2}}\right)$

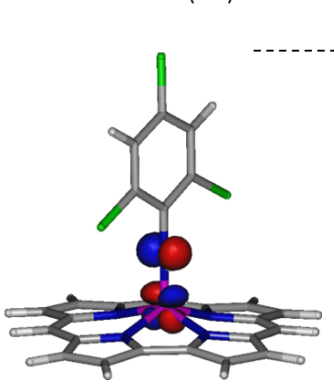

$\left(3 d_{x z}-2 p_{x}\right)^{*}$

localization

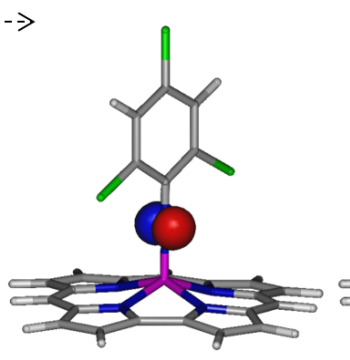

$N\left(2 p_{x}\right)$

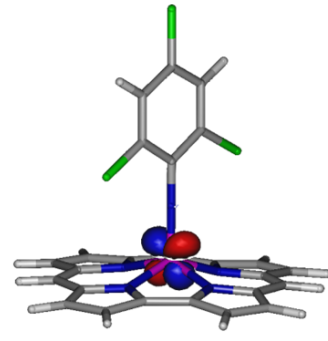

$\operatorname{Mn}\left(3 d_{x z}\right)$

Figure 7: Example of orbitals before and after the localization procedure (isocontour $=0.05$ ). $\sigma$ and $\left(3 \mathrm{~d}_{x z}-2 \mathrm{p}_{x}\right)$ bonding and anti-bonding couple of orbitals are transformed in metal, imide and corrole localized orbitals.

Table 4 summarizes the orthogonal valence bond analysis of the electronic structure of the four imido-complexes. For this purpose, the configurations of the CASSCF wave function have been classified by the number of electrons in the metal valence orbitals and the weight of the configurations has been summed for each subgroup, as shown in Table 4 . The wave function is dominated by configurations with 5 electrons on the Mn ion, but configurations with 4 or 6 electrons also contribute significantly. The weighted sum of the $d$-electrons in each configuration gives what we call the $d$-count, which is close to 5 in all complexes except for $[\mathrm{Mn}(\mathrm{Cor})(\mathrm{NTs})]$ in the triplet state. As an example, for $[\mathrm{Mn}(\mathrm{Cor})(\mathrm{NMes})]$ in the singlet state this sum is performed as follows: $\left[\left(0.042 \times 7 e^{-}\left(\mathrm{Mn}^{0}\right)+0.227 \times 6 e^{-}\left(\mathrm{Mn}^{+}\right)+0.446 \mathrm{x}\right.\right.$ $\left.\left.5 e^{-}\left(\mathrm{Mn}^{2+}\right)+0.255 \times 4 e^{-}\left(\mathrm{Mn}^{3+}\right)+0.024 \times 3 e^{-}\left(\mathrm{Mn}^{4+}\right)\right) / 0.994\right]$. In a purely ionic model with a trianionic corrole and a dianionic imide ligand, one would rather expect a d-count of 2, corresponding to $\mathrm{Mn}^{\mathrm{V}}$. In the present analysis the effective charge differs from the formal 
charge and indicates that there is an important charge transfer from the coordination sphere to the $\mathrm{Mn}$ ion, which is probably better considered as an effective $\mathrm{Mn}^{2+}$ ion.

Table 4: Orthogonal valence bond analysis of the [10,12]-CASSCF wave function of the four imido-complexes. Electronic configurations in the wave function are grouped by the number of electrons in the $\mathrm{Mn} \mathrm{d}$-orbitals and the total weight is given as a percentage. The d-count is the weighted sum of electrons on the metal centre.

\begin{tabular}{cccccccc}
\hline & $\mathrm{Mn}^{0}\left(7 e^{-}\right)$ & $\mathrm{Mn}^{+}\left(6 e^{-}\right)$ & $\mathrm{Mn}^{2+}\left(5 e^{-}\right)$ & $\mathrm{Mn}^{3+}\left(4 e^{-}\right)$ & $\mathrm{Mn}^{4+}\left(3 e^{-}\right)$ & total weight & $\mathrm{d}$-count \\
\hline$[\mathbf{M n}(\mathbf{C o r})(\mathbf{N M e s})]$ & & & & & & & \\
$\mathrm{S}=0$ & 4.2 & 22.7 & 44.6 & 25.5 & 2.4 & 99.4 & $\mathbf{5 . 0 1}$ \\
$\mathrm{S}=1$ & 3.0 & 18.9 & 46.4 & 29.1 & 1.8 & 99.2 & $\mathbf{4 . 9 2}$ \\
{$[\mathbf{M n}(\mathbf{C z})(\mathbf{N M e s})]$} & & & & & & & \\
$\mathrm{S}=0$ & 4.2 & 22.3 & 43.8 & 26.3 & 2.9 & 99.4 & $\mathbf{4 . 9 9}$ \\
$\mathrm{S}=1$ & 2.7 & 17.9 & 45.9 & 30.5 & 2.2 & 99.2 & $\mathbf{4 . 8 8}$ \\
{$[\mathbf{M n}(\mathbf{C o r})(\mathbf{N t C l P h})]$} & & & & & & & \\
$\mathrm{S}=0$ & 4.5 & 23.6 & 44.8 & 24.5 & 2.1 & 99.4 & $\mathbf{5 . 0 4}$ \\
$\mathrm{S}=1$ & 3.9 & 22.1 & 45.9 & 25.3 & 1.8 & 99.0 & $\mathbf{5 . 0 1}$ \\
{$[\mathbf{M n}(\mathbf{C o r})(\mathbf{N T s})]$} & & & & & & & \\
$\mathrm{S}=0$ & 4.4 & 23.2 & 45.0 & 24.9 & 2.0 & 99.4 & $\mathbf{5 . 0 3}$ \\
$\mathrm{S}=1$ & 0.9 & 8.7 & 40.1 & 43.6 & 6.1 & 99.3 & $\mathbf{4 . 5 4}$ \\
\hline
\end{tabular}

The electron count of the coordination sphere around the metal centre can be treated in a similar way as the assignment of the Mn charge. In the present calculations, a standard two-electron dative bond from the trianionic corrole to Mn is represented with 2 electrons in the corrole or corrolazine $\sigma$ active orbital. As can be seen in Table 5, only half of the configurations corresponds to this situation. The other half has only one electron in the corrole or corrolazine $\sigma$-orbital. This corresponds to a strongly covalent $\mathrm{Mn} 3 \mathrm{~d}_{x^{2}-y^{2}-\sigma}$ bond. The present imido-Mn complexes are therefore not completely trianionic. With the same analysis the imido-to-metal charge transfer can be quantified by looking at the occupation of the three $2 \mathrm{p}_{x}, 2 \mathrm{p}_{y}$ and $2 \mathrm{p}_{z}$ active orbitals localized on the nitrogen atom. The fact that the electron count of these is close to 3.5 denotes that $\mathrm{N}-\mathrm{R}$ group transfers 2.5 electrons to the $\mathrm{d}$ orbitals of the metal centre. With more bent coordination angle and a stronger electron withdrawing $\mathrm{R}$ group $\left(\mathrm{SO}_{2}\right)$, in the case of $[\mathrm{Mn}(\mathrm{Cor})(\mathrm{NTs})]$ in the triplet state only 2 electrons are transferred to the metal centre. The smaller amount of charge transferred to Mn explains that although being favoured by the geometrical parameters, the triplet ground state in this complex is very close in energy to the singlet state. To sum up, the transfer of 
nearly 3 electrons ( 0.5 from corrole and 2.5 from imide) from the coordination sphere to the metal centre is the key to understand how TMs are stabilized in these imido-complexes. ${ }^{20}$

Table 5: Orthogonal valence bond analysis of the [10,12]-CASSCF wave function of the four imido-complexes. Electronic configurations in the wave function are grouped by the number of electrons in the corrole, corrolazine and imide ligands and the total weight is given as percentage.

\begin{tabular}{|c|c|c|c|c|c|c|c|c|}
\hline & $\operatorname{Cor}^{3-}\left(2 e^{-}\right)$ & $\operatorname{Cor}^{2-}\left(1 e^{-}\right)$ & Count & $\mathrm{R}-\mathrm{N}^{-}\left(5 e^{-}\right)$ & $\mathrm{R}-\mathrm{N}^{0}\left(4 e^{-}\right)$ & $\mathrm{R}-\mathrm{N}^{+}\left(3 e^{-}\right)$ & $\mathrm{R}-\mathrm{N}^{2+}\left(2 e^{-}\right)$ & Count \\
\hline \multicolumn{9}{|l|}{$[\mathrm{Mn}(\mathrm{Cor})(\mathrm{NMes})]$} \\
\hline $\mathrm{S}=0$ & 45.3 & 47.2 & 1.38 & 9.2 & 47.6 & 36.7 & 5.9 & 3.60 \\
\hline $\mathrm{S}=1$ & 35.4 & 54.4 & 1.26 & 12.5 & 58.8 & 24.9 & 2.9 & 3.82 \\
\hline \multicolumn{9}{|l|}{$[\mathrm{Mn}(\mathrm{Cz})(\mathrm{NMes})]$} \\
\hline $\mathrm{S}=0$ & 43.7 & 48.3 & 1.36 & 10.6 & 48.5 & 34.8 & 5.4 & 3.65 \\
\hline $\mathrm{S}=1$ & 35.3 & 54.3 & 1.26 & 14.0 & 59.3 & 23.2 & 2.6 & 3.86 \\
\hline \multicolumn{9}{|l|}{$[\mathrm{Mn}(\mathrm{Cor})(\mathrm{NtClPh})]$} \\
\hline $\mathrm{S}=0$ & 44.0 & 48.0 & 1.36 & 9.3 & 46.5 & 37.1 & 6.4 & 3.59 \\
\hline $\mathrm{S}=1$ & 31.1 & 55.8 & 1.19 & 12.8 & 56.0 & 27.2 & 3.1 & 3.79 \\
\hline \multicolumn{9}{|l|}{$[\mathrm{Mn}(\mathrm{Cor})(\mathrm{NTs})]$} \\
\hline $\mathrm{S}=0$ & 44.8 & 47.6 & 1.37 & 9.5 & 46.2 & 36.9 & 6.6 & 3.59 \\
\hline $\mathrm{S}=1$ & 34.7 & 55.2 & 1.25 & 30.2 & 57.8 & 9.7 & 0.9 & 4.19 \\
\hline
\end{tabular}

\section{Conclusions}

The computational study presented here shows that the axial N-R ligand plays a fundamental role in the relative stability of the electronic states with different spin moment. The combination of DFT geometry optimizations and CASPT2 single-point calculations results in a description of the relative energies of the singlet and triplet coupled states that is consistent with the experimental information on four different imido-Mn corrole and corrolazine complexes. The DFT optimized geometries show identical corrole and corrolazine coordination distances in singlet and triplet, but important variations are observed in the coordination of the axial ligand. The singlet presents short distances and linear coordination, while the bond distance is longer for the triplet coupling and the axial ligand also has a marked tendency to coordinate in a bend fashion. Furthermore, it is observed that electron withdrawing groups in the axial ligand reduce the $\pi$ interaction between metal and ligand and reduce the gap between the two singly occupied orbitals of the triplet state, and hence, stabilizing it with respect to the singlet state. Hence, it is not unexpected that the system with the strongest 
electron withdrawing group, the NTs complex, has a triplet ground state.

The orthogonal valence bond reading of the wave functions reveals important electron charge transfers from both the corrole/corrolazine ligand and the axial ligands to the $\mathrm{Mn}$. The formal charge of $\mathrm{Mn}$ within an ionic model of the complexes corresponds to $\mathrm{Mn}^{5+}$. However, the wave function shows that this high charge is reduced to an effective charge of $2+$ by a transfer of nearly three electrons ( 2.5 from the axial ligand and 0.5 from the corrole/corrolazine) to the metal centre.

Supporting Information Available: Relevant geometrical parameters for all states obtained from BP86/def2-TZVP, Cartesian coordinates and energies (BP86/def2-TZVP, [10,12]CASSCF and [10,12]-CASPT2 with Basis I and Basis II) for all the optimized geometries, plots of the $[10,12]$-CASSCF active orbitals and their occupation numbers and plots of the localized $[10,12]$-CASSCF active orbitals used in the wave function analysis.

\section{Acknowledgement}

Financial support has been provided by the Spanish Administration (Project CTQ201451938-P), the Generalitat de Catalunya (Projects 2014SGR199 and Xarxa d'R+D+I en Química Teòrica i Computacional, XRQTC) and the European Union (COST Action ECOSTBio CM1305). The Flemish Science Foundation (FWO) is acknowledged for financial support. Computational resources and services used in this work were provided by the VSC (Flemish Supercomputer Center), funded by the Hercules Foundation and the Flemish Government - department EWI. 


\section{References}

(1) Groves, J.; Kruper, W.; Haushalter, R. J. Am. Chem. Soc. 1980, 102, 6375-6377.

(2) Breslow, R.; Gellman, S. J. Chem. Soc., Chem. Commun. 1982, 1400-1401.

(3) Breslow, R.; Gellman, S. J. Am. Chem. Soc. 1983, 105, 6728-6729.

(4) Groves, J.; Takahashi, T. J. Am. Chem. Soc. 1983, 105, 2073-2074.

(5) Svastits, E.; Dawson, J.; Breslow, R.; Gellman, S. J. Am. Chem. Soc. 1985, 107, 64276428.

(6) Jin, N.; Bourassa, J.; Tizio, S.; Groves, J. Angew. Chem. Int. Ed. 2000, 39, 3849.

(7) Jin, N.; Ibrahim, M.; Spiro, T.; Groves, J. J. Am. Chem. Soc. 2007, 129, 12416-12417.

(8) Song, W.; Seo, M.; George, S.; Ohta, T.; Song, R.; Kang, M.; Tosha, T.; Kitagawa, T.; Solomon, E.; Nam, W. J. Am. Chem. Soc. 2007, 129, 1268-1277.

(9) Jin, N.; Groves, J. J. Am. Chem. Soc. 1999, 121, 2923-2924.

(10) De Angelis, F.; Jin, N.; Car, R.; Groves, J. Inorg. Chem. 2006, 45, 4268-4276.

(11) Latifi, R.; Tahsini, L.; Karamzadeh, B.; Safari, N.; Nam, W.; de Visser, S. Arch. Biochem. Biophys. 2011, 507, 4-13.

(12) Jasat, A.; Dolphin, D. Chem. Rev. 1997, 97, 2267-2340.

(13) Paolesse, R.; Nardis, S.; Sagone, F.; Khoury, R. J. Org. Chem. 2001, 66, 550-556.

(14) Johnson, A.; Kay, I. Proc. Chem. Soc. 1964, 89.

(15) Gross, Z.; Galili, N.; Saltsman, I. Angew. Chem. Int. Ed. 1999, 38, 1427-1429.

(16) Gross, Z.; Galili, N.; Simkhovich, L.; Saltsman, I.; Botoshansky, M.; Blaser, D.; Boese, R.; Goldberg, I. Org. Lett. 1999, 1, 599-602. 
(17) Gross, Z. J. Biol. Inorg. Chem. 2001, 6, 733-738.

(18) Aviv, I.; Gross, Z. Chem. Commun. 2007, 1987-1999.

(19) Aviv, I.; Gross, Z. Chem. Eur. J. 2009, 15, 8382-8394.

(20) Pierloot, K.; Zhao, H.; Vancoillie, S. Inorg. Chem. 2010, 49, 10316-10329.

(21) Berg, S.; Thomas, K.; Beavers, C.; Ghosh, A. Inorg. Chem. 2012, 51, 9911-9916.

(22) Thomas, K.; Alemayehu, A.; Conradie, J.; Beavers, C.; Ghosh, A. Acc. Chem. Res. 2012, 45, 1203-1214.

(23) Zhao, H.; Pierloot, K.; Langner, E.; Swarts, J.; Conradie, J.; Ghosh, A. Inorg. Chem. 2012, 51, 4002-4006.

(24) Alemayehu, A.; Gagnon, K.; Terner, J.; Ghosh, A. Angew. Chem. Int. Ed. 2014, 53, $14411-14414$.

(25) Capar, J.; Conradie, J.; Beavers, C.; Ghosh, A. J. Phys. Chem. A 2015, 119, 34523457.

(26) Roos, B.; Veryazov, V.; Conradie, J.; Taylor, P.; Ghosh, A. J. Phys. Chem. B 2008, 112, 14099-14102.

(27) Vazquez-Lima, H.; Norheim, H.-K.; Einrem, R.; Ghosh, A. Dalton Trans. 2015, 44, $10146-10151$.

(28) Ramdhanie, B.; Stern, C.; Goldberg, D. J. Am. Chem. Soc. 2001, 123, 9447-9448.

(29) Kerber, W.; Goldberg, D. J. Inorg. Biochem. 2006, 100, 838-857.

(30) Goldberg, D. P. Acc. Chem. Res. 2007, 40, 626-634.

(31) Liu, H.; Mahmood, M.; Qiu, S.; Chang, C. Coord. Chem. Rev. 2013, 257, 1306-1333. 
(32) Gross, Z.; Golubkov, G.; Simkhovich, L. Angew. Chem. Int. Ed. 2000, 39, 4045-4047.

(33) Liu, H.; Lai, T.; Yeung, L.; Chang, C. Org. Lett. 2003, 5, 617-620.

(34) Gross, Z.; Gray, H. Adv. Synth. Catal. 2004, 346, 165-170.

(35) Kumar, A.; Goldberg, I.; Botoshansky, M.; Buchman, Y.; Gross, Z. J. Am. Chem. Soc. 2010, 132, 15233-15245.

(36) Mandimutsira, B.; Ramdhanie, B.; Todd, R.; Wang, H.; Zareba, A.; Czemuszewicz, R.; Goldberg, D. J. Am. Chem. Soc. 2002, 124, 15170-15171.

(37) Lansky, D.; Mandimutsira, B.; Ramdhanie, B.; Clausen, M.; Penner-Hahn, J.; Zvyagin, S.; Telser, J.; Krzystek, J.; Zhan, R.; Ou, Z.; Kadish, K.; Zakharov, L.; Rheingold, A.; Goldberg, D. Inorg. Chem. 2005, 44, 4485-4498.

(38) Lansky, D.; Goldberg, D. Inorg. Chem. 2006, 45, 5119-5125.

(39) Eikey, R. A.; Khan, S. I.; Abu-Omar, M. M. Angew. Chem. Int. Ed. 2002, 41, 35923595.

(40) Edwards, N.; Eikey, R.; Loring, M.; Abu-Omar, M. Inorg. Chem. 2005, 44, 3700-3708.

(41) Lansky, D. E.; Kosack, J. R.; Sarjeant, A. A. N.; Goldberg, D. P. Inorg. Chem. 2006, $45,8477-8479$.

(42) Zdilla, M. J.; Abu-Omar, M. M. J. Am. Chem. Soc. 2006, 128, 16971-16979.

(43) Abu-Omar, M. Dalton Trans. 2011, 40, 3435-3444.

(44) Weigend, F.; Haser, M.; Patzelt, H.; Ahlrichs, R. Chem. Phys. Lett. 1998, 294, 143-152.

(45) Weigend, F.; Ahlrichs, R. Phys. Chem. Chem. Phys. 2005, 7, 3297-3305.

(46) Perdew, J. Phys. Rev. B 1986, 33, 8822-8824. 
(47) Becke, A. Phys. Rev. A 1988, 38, 3098-3100.

(48) Ahlrichs, R.; Bar, M.; Haser, M.; Horn, H.; Kolmel, C. Chem. Phys. Lett. 1989, 162, $165-169$.

(49) Alvarez-Moreno, M.; de Graaf, C.; Lopez, N.; Maseras, F.; Poblet, J.; Bo, C. J. Chem. Inf. Model. 2015, 55, 95-103 (http://dx.doi.org/10.19061/iochem-bd-2-4).

(50) Aquilante, F.; De Vico, L.; Ferre, N.; Ghigo, G.; Malmqvist, P.-A.; Neogrady, P.; Pedersen, T.; Pitonak, M.; Reiher, M.; Roos, B.; Serrano-Andres, L.; Urban, M.; Veryazov, V.; Lindh, R. J. Comput. Chem. 2010, 31, 224-247.

(51) Roos, B.; Lindh, R.; Malmqvist, P.-.; Veryazov, V.; Widmark, P.-O. J. Phys. Chem. A 2004, 108, 2851-2858.

(52) Roos, B.; Lindh, R.; Malmqvist, P.-.; Veryazov, V.; Widmark, P.-O. J. Phys. Chem. A 2005, 109, 6575-6579.

(53) Pierloot, K.; Dumez, B.; Widmark, P.-O.; Roos, B. Theor. Chim. Acta 1995, 90, 87114.

(54) Pierloot, K. Int. J. Quantum Chem. 2011, 111, 3291-3301.

(55) Miralles, J.; Daudey, J.; Caballol, R. Chem. Phys. Lett. 1992, 198, 555-562.

(56) Miralles, J.; Castell, O.; Caballol, R.; Malrieu, J. J. Chem. Phys. 1993, 172, 33-43.

(57) Ben Amor, N.; Maynau, D. Chem. Phys. Lett. 1998, 286, 211-220.

(58) Maynau, D.; Evangelisti, S.; Guihery, N.; Calzado, C.; Malrieu, J. J. Chem. Phys. 2002, 116, 10060-10068.

(59) Calzado, C.; Evangelisti, S.; Maynau, D. J. Phys. Chem. A 2003, 107, 7581-7588.

(60) Ben Amor, N.; Bessac, F.; Hoyau, S.; Maynau, D. J. Chem. Phys. 2011, 135, 014101. 
(61) De Visser, S.; Ogliaro, F.; Gross, Z.; Shaik, S. Chem. Eur. J. 2001, 7, 4954-4960.

(62) Ghosh, A.; Taylor, P. Current Opinion in Chemical Biology 2003, 7, 113-124.

(63) Swart, M.; Groenhof, A.; Ehlers, A.; Lammertsma, K. J. Phys. Chem. A 2004, 108, $5479-5483$.

(64) Chen, H.; Lai, W.; Shaik, S. J. Phys. Chem. B 2011, 115, 1727-1742.

(65) Pierloot, K.; Vancoillie, S. J. Chem. Phys. 2006, 125, 124303-10329.

(66) Pierloot, K.; Tsokos, E.; Roos, B. Chem. Phys. Lett. 1993, 214, 583-590.

(67) Pierloot, K.; Phung, Q.; Domingo, A. To be published.

(68) Shaik, S.; Hiberty, P. A Chemist's Guide to Valence Bond Theory; Wiley, 2007.

(69) Wu, W.; Su, P.; Shaik, S.; Hiberty, P. Phys. Chem. Chem. Phys. 2011, 111, 7557-7593.

(70) Radon, M.; Broclawik, E.; Pierloot, K. J. Phys. Chem. B 2010, 114, 1518-1528.

(71) Zapata-Rivera, J.; Caballol, R.; Calzado, C. Phys. Chem. Chem. Phys. 2011, 13, 2024120247.

(72) Zapata-Rivera, J.; Caballol, R.; Calzado, C. J. Comput. Chem. 2011, 32, 1144-1158.

(73) Zapata-Rivera, J.; Caballol, R.; Calzado, C. J. Comput. Chem. 2012, 33, 1407-1415.

(74) Sadoc, A.; Broer, R.; de Graaf, C. J. Chem. Phys. 2007, 126, 134709.

(75) Sadoc, A.; Broer, R.; de Graaf, C. Chem. Phys. Lett. 2008, 454, 196-200. 
For Table of Contents Only

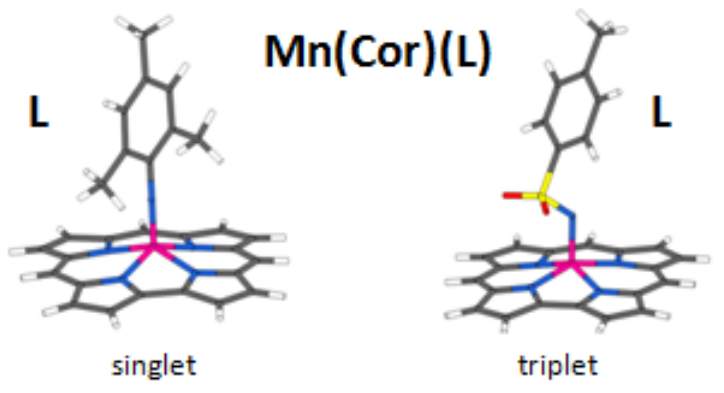

Multiconfigurational perturbation theory energy calculations on DFT optimized geometries of four Mn corrole and corrolazine are reported to clarify the role of the axial imide ligand on the relative stability of the low-lying magnetic states of these complexes. The analysis of the multiconfigurational wave function provides insights of how both equatorial corrole/corrolazine and axial imide ligands stabilize the formally $\mathrm{Mn}^{\mathrm{V}}$ ion. 